\title{
Hamlet und der Melancholiker in „,Kants Beobachtungen über das Gefühl des Schönen und Erhabenen".
}

Von Dr. Tim Klein.

Nicht um die berufene „empfindliche Lücke" auszufüllen, welche sich in der Reihe der Erklärungen des Hamletcharakters etwa noch fände, sondern nur um einen kleinen Beitrag zur Bewährung des von Kant in den „Beobachtungen über das Gefühl des Schönen und Erhabenen" aufgestellten melancholischen Typus zu liefern, sind diese Zeilen geschrieben. Sie wollen zeigen, wie glücklich und scharf Kant dort das melancholische Temperament aufgefasst und dargestellt hat. Kant hält ebenso wie Shakespeare die alte Bestimmung und Einteilung der Temperamente für zutreffend. Hamlet ist -- mag er im übrigen was sonst sein, etwa das Genie schlechthin - auf jeden Fall Melancholiker. Sein Selbstzeugnis (Akt II, Scene 2, Ende) spricht klar aus, was das ganze Stïck verrät. Wenn auch Hamleț Individualität, wie dies gewiss ist, über jenen Typus weit hinausragt, so wird man doch in Erstaunen versetzt über die frappante Ähnlichkeit des Individuums Hamlet mit dem Typus, wie ihn Kant gezeichnet hat. Verzichtet man für einen Augenblick auf metaphysische Ausdeutungen und hält sich ausschliesslich an die psychologische Analyse, so wird man finden, dass aus dem Kantischen Typus - nicht über das ganze Antlitz - aber in scharfen Hauptz.̈̈gen und in manchen schwächeren Nebenlinien Hamlet hervorschaut. Fin merkwürdiges Zusammentreffen der Konzeption des Philosophen mit der des Dichters!

Zuvörderst beschreibt Kant im Eingang seiner Schilderung des Melancholikers (1. Druck 1771 S. 27) sogleich den allgemeinen Habitus und den Spezialfall Hamlets. "Ein innigliches Gefühl für die Schönheit und Würde der menschlichen Natur, und eine Fassung und Stärke des Gemüths hierauf, als 
auf einen allgemeinen Grund, seine gesamte Handlungen zu beziehen, ist ernsthaft, und gesellet sich nicht wohl mit einer flatterhaften Lustigkeit, noch mit dem Unbestande eines Leichtsinnigen. Es nähert sich so gar der Schwermuth, einer sanften und edlen Empfindung, in so fern sie sich auf dasjenige Grausen gründet, das eine eingeschränkte Seele kühlt (fühlt!), wenn sie, von einem grossen Vorsatze voll, die Gefahren sieht, die sie zu überstehen hat, und den schweren, aber grossen Sieg der Selbstüberwindung vor Augen hat." „Der, dessen Gefühl ins Melancholische einschlägt, wird nicht darum so genannt, weil er, der Freuden des Lebens beraubt, sich in finsterer Schwermuth härmet, sondern weil seine Empfindungen, weun sie über einen gewissen Grad vergrössert würden, oder durch einige Ursachen eine falsche Richtung bekämen, auf dieselbe leichter als auf einen anderen Zustand auslaufen würden."

Vor allem aber ist der klaffende Gegensatz, der Hamlets Seele spaltet, mit der Bestimmung: „Er hat vorzüglich ein Getühl für das Erhabene“ gegeben, wenn nun dieses Gefühl bei Hamlet niedergeschlagen wird durch die sich in seiner nächsten Umgebung offenbarende Niedrigkeit der Triebe: neben seinem erhabenen Vater, Apollo - Claudius der Satyr u. s. w.

Die feine Unterscheidung Kants, dass Melancholie unter besonderen Umständen, nicht notwendig, auf Schwermut hinausläuft, trifft durchaus auf Hamlet zu. Am nächsten kommt Kants Auffassung des Melancholikers der Goetheschen Deutung des Hamlet. Die „eingeschränkte“ Seele, von einem grossen Vorsatz voll und im Angesichte der grossen Gefahren von Grausen erfüllt, stimmt zu dem köstlichen, aber engeren Gefässe, das nur liebliche Blumen in seinem Schoss hätte aufnehmen sollen und das der Eichbaum auseinandersprengt.

Die souveräne Selbständigkeit, mit welcher Hamlet der Welt gegenübersteht, forschend, grübelnd, ja gewissermassen experimentierend (die Pantomime!) findet sich beim Melancholiker Kants mit den Worten ausgedrückt: „Der Mensch von melancholischer Gemüthsverfassung bekümmert sich wenig darum, was andere urtheilen, was sie für gut oder wahr halten, er stützet sich desfalls bloss auf seine eigene Einsicht. Weil die Bewegungsgründe in ihm die Natur der Grundsätze annehmen: so ist er nicht leicht auf andere Gedanken zu bringen; seine Standhaftigkeit artet auch 
bisweilen in Eigensinn aus." So ist Hamlet von dem Motiv der Rache wie von einer Idiosynkrasie beherrscht, im Buche seiner Seele ist ganz allein das Rachegebot eingeschrieben, es ist ihm alleinige Losung, heiliger Schwur.

„Freundschaft ist erhaben und daher für sein Gefühl... Selbst das Andenken der erloschenen Freundschaft ist ihm noch ehrwürdig." Man braucht sich hier nur der Freundschaft Hamlets mit Horatio und der herrlichen Worte an diesen Freund zu erinnern (III. Akt, 2. Scene, Vers 59-79) und der überschwenglichen Worte, mit denen er der Liebe zu Ophelien gedenkt (III, 1, Vers 292-94), um in Kants Worten mehr als eine vage Ähnlichkeit zu sehen.

"Gesprächigkeit ist schön, gedankenvolle Versehwiegenheit erhaben. Er ist ein guter Verwahrer seiner und anderer Geheimnisse." Man vergleiche die Verachtung des Schwätzers Polonius und Akt III, Scene 6, 9-13, ferner I, 5. Scene.

„Wahrhaftigkeit ist erhaben, und er hasset Lügen oder Verstellung." Hamlets Verstellung entspringt dem Zweifel über die Wahrhaftigkeit des Geistes, ebenso die Inscenierung der Pantomime dem Bedürfnis, vollkommene Klarheit zu bekommen; der Falschheit, die ihn ausholen will (Rosenkranz und Güldenstern), begegnet er mit Verachtung und Stolz.

„Er hat ein hohes Gefühl von der Würde der menschlichen Natur.“ Die klassische Stelle hiefür ist die Äusserung gegen Rosenkranz und Güldenstern: „Welch ein Meisterstück ist der Mensch!“ u. s. f.

„Er duldet keine verworfene Unterthänigkeit, und athmet Freyheit in einem edlen Busen. Alle Ketten, von denen vergoldeten an, die man am Hofe trägt, bis zu dem schweren Eisen des Galeerensclaven sind ihm abscheulich;" - Dänemark ist dem Hamlet ein Gefängnis, weil in ihm die Gewalt herrscht, die durch Mord zur Herrschaft kam. Sein königlich offener Sinn verhöhnt die Liebedienerei des Polonius, der in einem Atem die Wolke für ein Kameel und ein Wiesel erklärt.

„Er ist ein strenger Richter seiner selbst und anderer, und nicht selten seiner so wohl, als der Welt überdrüssig." Dieser Zng ist so offenkundig hamletisch, dass er keines Beleges bedarf, so wenig wie die folgenden:

„In der Ausartung dieses Charakters neiget sich die Ernsthaftigkeit zur Schwermuth, die Andacht zur Schwärmerey, 
der Freyheitseifer zum Enthusiasmus. Beleidigung und Ungerechtigkeit zünden in ihm Rachbegierde an. Er ist dann sehr zu fürchten." Hamlet: „Denn ob ich schon nicht jäh und heftig bin, So ist doch was Gefährliches in mir, Das ich zu scheun Dir rate." Und wie Hamlet sich tollkühn in die Gefahr stürzt, so der Melancholiker: „Er trotzet der Gefahr, und verachtet den Tod.“ Endlich: „Bey der Verkehrtheit seines Gefühls und dem Mangel einer aufgeheiterten Vernunft verfällt er aufs Abentheuerliche.“ - - Soweit die sich aufdrängenden Ähnlichkeiten.

Es will uns im übrigen scheinen, als sei mit dem Umschlag der optimistischen in die entgegengesetzte pessimistische Weltauffassung, wie sie besonders Hermann Türck und Kuno Fischer betonen, nicht das Richtige gesagt - so blendend die Antithese auch ist. Obwohl natürlich Kant nicht entfernt auf den Hamlet exemplificiert hat, so giebt er doch einen entscheidenden Hinweis durch die Bemerkung: "er hat vorzüglich ein Gefühl für das Erhabene." Der Optimist glaubt in der besten der Welten zu leben, der Pessimist in der schlechtesten; anders der Mensch, welchen die Grundstimmung des Erhabenen beseelt. Er weiss, dass die erscheinende Welt schlecht ist, aber er glaubt auch, dass sich das Grosse und Erhabene in ihr offenbart. Er steht von vornherein - wie dies bei Schiller z. B. klar hervortritt - in einem satirischen Grundverhältnis zur erscheinenden Welt. Das trifft auf Hamlet zu. Seine Sarkasmen sind die Pfeile des erhabenen Satirikers. Liesse er in dieser Grundstimmung einen Augenblick nach, dann wäre der quälende Dorn des Widerspruchs ans seiner Seele gezogen. Aber das geschieht nicht. Er hält am Erhabenen fest, nur erscheint ihm nicht eben Claudius oder seine Mutter oder Polonius so. - Aber sein Vater bleibt ihm gleich gross, Horatio gleich gut, Fortinbras in seiner erhabenen Gesinnung gleich bewunderungswürdig. Dem wirklich Erhabenen gegenüber also verhält er sich durchaus positiv, bejahend. Die Antithese: Optimismus und Pessimismus setzt einen radikalen Bruch im Charakter Hamlets voraus, einen vollständigen Umschlag. Gerade die Bewunderung des naiven Helden Fortinbras ist bei einem gebeizten Pessimisten eine bare Unmöglichkeit. Welche Worte findet er der Mutter gegenüber, um den Segen der Übung im Guten zu preisen, mag auch die satirische Grundstimmung wieder durchbrechen! - das thut kein Pessimist. Der 
Optimist denkt wohlwollend vom Menschen, sein Element ist der Humor. Der Pessimist denkt schlecht rom Menschen, sein Element ist die Verachtung, der Hass. Der Mensch mit erhabener Gesinnung denkt gross vom Menschen, sein Element ist positiv Enthusiasmus, negativ Satire; ist er Melancholiker, dann tritt hinzu der Schmerz als Stimmung, die Schwermut. Und so ist Hamlet beschaffen. Was ihn zerstört, ist nicht ein kompleter Bruch seiner Natur, sondern sein dem Grossen, Erhabenen zugeneigtes Wesen - und eben dies ist tragisch in einer Welt der Niedertracht. - Damit soll keineswegs Shakespeares Wunderwerk "erklärt" sein - sondern von Kant ausgehend ist vielleicht ein Wink zu empfangen, um die oben genannte Antithese zu überwinden, die vor allem auch noch den Fehler in sich schliesst, dass sie die Verzweiflung voraussetzt. Es ist keine Frage, dass Hamlet am Abgrund der Verzweiflung umhertaumelt; der verstellte Wahnsinn verstärkt noch diesen Eindruck. Aber da es eben verstellter Wahn ist, muss dieser Eindruck von seinem wirklichen Zustand abgezogen werden. Und endlich setzt jene Auffassung an die Stelle der Entwickelung des Charakters, die bei der satirischen, verneinenden Grundstimmung des Erhabenen möglich und notwendig so ist, wie sie ist, - den Bruch, den vollständigen Umschlag des Charakters, das heisst im Grunde eine psychologische Unmöglichkeit. 